\title{
Memory and Mental States in the Appreciation of Literature
}

\author{
Marisa Bortolussi and Peter Dixon
}

\begin{abstract}
An implicit supposition in literary studies is that ideal readers have unconstrained access to the text. However, we argue instead that the processing of literary narrative must be mediated by the fragmentary and distorted memory of real readers. In the present chapter, we focus on an important determinant of memory: the variation in readers' mental states during reading. In particular, we identify two prevalent fluctuations that have critical implications for memory and literary appreciation: mind wandering, in which the reader momentarily gives relatively little priority to processing the text; and engagement, in which the reader constructs elaborate and personally meaningful representations of the story world. We describe how the variation in these mental states over the course of reading affects reading processes and determines memory for both text and aesthetic reactions. This analysis is supported by the results of two experiments in which readers' mental states were probed online during reading.
\end{abstract}

Keywords Narrative processing • Cognitive psychology • Memory • Mental states • Mind wandering

\section{Introduction}

One of the most profound but least understood insights concerning literature is the phenomenological idea that, until read and processed by readers, literary works are merely physical objects. As Escarpit (1966) put it, "when we hold a book in our hands, all we hold is paper. The book is elsewhere" (p. 7). Today, no one would dispute the intuitive metaphor that works come alive in the minds of their readers. But what precisely this entails is still the object of considerable debate. At the heart of the controversy are some thorny issues: the nature of the text, the nature of

\author{
M. Bortolussi $(\bowtie)$ \\ Department of Modern Languages and Cultural Studies, University of Alberta, Alberta, Canada \\ e-mail: marisa.bortolussi@ualberta.ca \\ P. Dixon \\ Department of Psychology, University of Alberta, Alberta, Canada
}

(C) The Author(s) 2015

P.F. Bundgaard, F. Stjernfelt (eds.), Investigations Into the Phenomenology

and the Ontology of the Work of Art, Contributions To Phenomenology 81,

DOI 10.1007/978-3-319-14090-2_3 
the reader's processing, and the relationship between texts and their readers. More specifically, we need to resolve whether the text can be considered an objective entity and to what extent it can be reproduced in readers' minds. Ingarden (1973) and Iser (1978) were inspired by ideas from phenomenology and acknowledged the active role of reading. However, their reader was nonetheless conceived of as a textual counterpart with little creative license, the text was conceived of as an objective entity, and the reading process was conceived of as a decoding activity. Implicit in this conceptualization is the fundamental assumption that aesthetic response is to the objective text as reproduced in readers' minds during the reading process. But these assumptions, which continue to pervade literary studies, are undermined by an abundance of psychological evidence that has emerged in cognitive psychology and discourse processing. This research sheds light on some of the real limitations of human memory and attention and their consequences for reading and readers' mental representations of text. In particular, it indicates that comprehension is not just a text-driven process but also a constructive activity. That is, mental representations are not reproductions of text but rather more schematic "situation models," dependent to a large extent on both the reading context and reader variables such as mental states, capacities, interests, goals, and so on. Thus, any appreciation or aesthetic response cannot properly be thought of as related to the text per se but rather to this reconstructed representation of the text. When considered seriously, this body of research leads us to some fundamental revisions of phenomenological accounts of literary processing and aesthetic response.

We begin by identifying and briefly reviewing some of the prevailing assumptions concerning the appreciation of literature in some branches of literary studies. This is followed by a summary of relevant psychological research, and especially the constraints on the cognitive processes of attention and memory. Finally, we describe two experiments that provide evidence for a revised model of literary processing and response. This new approach takes into account how readers' mental states fluctuate over the course of the reading and how such fluctuations affect their mental representations of, and aesthetic response to, the text.

\section{Literary Studies}

In his extensive 1931 work, Ingarden explained that due to the finite and limited nature of literary texts, objects can only be partially represented, and the gaps in the representation, which he calls "spots of indeterminacy," must be fleshed out by the reader. He identifies two such processes: "concretization" and "filling-out" or completion. "Concretization" refers to the reader's active representation of what has actually been mentioned in the text; "filling-out" refers to the reader's representation of what is not mentioned in the text. Since different readers respond differently, the results of the concretization and completion processes can be innumerable. Although Ingarden recognized this inevitable fact, he by no means believed that any concretization or completion was acceptable. As Bundgaard (2013) explains: 
"idiosyncratic associations foreign to the meaning universe of the artwork [...] can rationally be rejected as irrelevant" (p. 175). For this reason, as Holub (1995) explained, Ingarden specified that not all concretizations are licensed by the text but rather that "they must be based on a faithful and accurate reconstruction of the text" (p. 302). Used in this sense, the word "reconstruction" refers to a process of decoding and implies that texts are objective entities that can be faithfully reproduced in readers' minds. Following in his mentor's footsteps, Iser (1974) agreed that meaning does not reside in the text, but rather arises in the interaction between reader and text. However, like Ingarden he allowed for only a minimal margin of creativity: Readers may supply trivial details not provided by the text, such as the color of a character's hair, but their processing must conform to the demands of the text. His "implied reader" was in fact a hypothetical correlative of the text, an idealized projection of what is presumed to be a stable, objective encoding of an intention.

Many traditions of literary scholarship betray the persistence of this phenomenological legacy in their descriptions of literary texts and the presumed effects of textual features. Below, we consider, in turn, the positions of narratologists and stylisticians. Both groups of literary scholars at least implicitly endorse the structuralist Culler's (1975) understanding of the text as an objective entity, decodable by competent, ideal readers who have mastered the literary conventions required for successful comprehension.

To begin with, narratologists also seem to share this sensitivity. When one aggregates the vast quantity of features and devices that narratologists deem important for competent readers to notice, track, remember, and associate in textually mandated ways, one is lead to the inevitable conclusion that the competent reader is nothing short of a super reader, endowed with a super brain. With respect to just the characters in the story, readers must notice and remember who said what to whom; who thought what and when in what kind of language; who was where at any given point in the story; and who noticed what and where; who knew what and when, and so on. The cognitive narratologist Lisa Zunshine (2006) echoes this intuitive expectation by stating that "the ability to keep track of who thought what, and felt what, and when they thought of it, is crucial" (p. 60). Furthermore, with respect to the discourse, readers must also notice and decipher all the metaphors, similes, and grammatical and syntactical deviations, and they must distinguish between narrator and character discourse and relate those entities to a narrating agent. Besides tracking all of this information, they must also retain it in working memory so as to make necessary associations and periodically update their inferences. As well, all of this processing must be informed by all of the relevant literary conventions and traditions, presumably encoded in readers' long-term memory and retrieved effortlessly as needed. The theoretical assumption is that all relevant textual features are noticed, tracked, interpreted, and remembered. Although no narratologist has claimed that such copious amounts of information can be processed in one reading, the implicit assumption is that is achievable through a series of different activities, such as rereading and note taking. However, the assumption is undermined by the contradictions and debates arising in narratologists' own laborious attempts 
to identify the features and devices of narrative texts. Well-known polemics, such as the discussion of within-sentence shifts in speech and thought representation (Bal 1977) or the more than 40 years of theorizing about the nature and features of focalization (Bronzwaer 1981; Fludernik 2001; Nieragden 2002; Herman and Vervaeck 2004; Margolin 2009; Klauk 2012), suggest that defining what is in the text is often reader (and narratologist) dependent, with the result that mental representations of the text differ even with careful, scholarly analysis.

Second, within stylistics, one issue that has received considerable attention is the notion of foregrounding. Like Ingarden, Iser, the structuralists, and the narratologists, stylisticians assumed that foregrounding could be objectively defined, a belief that lead to the establishment of toolkits of foregrounding features (e.g., Leech and Short 2007). Wishing to advance our understanding of the function of foregrounded features, some scholars in the empirical studies of literature attempted to investigate their effect on real readers (van Peer 1986; Miall and Kuiken 1994). However, as Sanford and Emmott (2012, pp. 82-83) cogently demonstrated, empirical studies of the forms and functions of foregrounding in particular texts have been methodologically flawed. One of the main weaknesses, they explained, is that the determination of which textual features can be considered foregrounding devices is the product of inconsistent, subjective judgments. The second is that the relationship between features and effects in these studies is merely correlational, not causal: Because foregrounding features were studied in situ, we have no evidence that any of these features have a causal effect on readers' response. They may or may not be noticed, they may or may not form part of the reader's mental representation of the text, and they may or may not be retained in memory. Indeed, van Peer's (1986) seminal study demonstrated very weak memory for foregrounded elements. In sum, while theoretical concepts such as the ideal reader allow us to anticipate a variety of possible text-consistent responses that could potentially arise, the evidence for effects of foregrounding in actual readers is not overwhelming.

As we demonstrate throughout the remainder of this chapter, no reader's processing can ever reproduce the original text, owing in part to the limitations of human memory implicated in the reading process. Reading, like stories, unfolds over time. This may seem like a trivial fact, yet its implications for mental processing have yet to be fully appreciated. Precisely because reading is a temporal process, every portion of a read text is consigned to memory, and therefore must be retrieved from memory. At any one moment, only a small window on the text is immediately available for processing and for detailed inferences. As the reader progresses through the story, this window scrolls over the text, with the previous content continually replaced by current portions. Thus, short sequences of text are only available in the window for a limited period of time, and then they are gone (cf. Fletcher 1986). In other words, the full text is never present in a reader's mind. If any information is relevant for understanding subsequent aspects of the text, it must be retrieved from memory at that later point. This retrieval might be optimal for an ideal reader with ideal memory. However, as will be demonstrated in the following section, human memory is by nature incomplete and distorting; anything consigned to memory must be pieced together from fragmentary and fallible memory traces 
(cf. Bortolussi and Dixon 2013). Therefore, the very nature of the human mind renders complete reproductions of the text impossible. In turn, this implies that the aesthetic response engendered by the text is not, precisely speaking, a response to the text. Rather, it is a response to the reader's own mental representation of the text, with all of the limitations that implies.

Because everything that is read is consigned to memory, all aspects of literary response-comprehension, emotional reactions, inferences, interpretations, and appreciation-are mediated by memory. All of these processes are dependent on what we recall about characters' conversations, spatial configurations, the narrator's status and discourse particulars, stylistic devices, and so on. Once the memorydependent basis of literary processing is acknowledged, one must acknowledge that aesthetic response is to the reader's representation of the text. As we describe in the following section, that representation can only be a distilled, schematic outline of the text.

\section{Evidence on Memory for Text}

As we have argued previously, the limitations of human memory are well appreciated in cognitive psychology. For the present purposes, two well-known facts about memory are central: First, far from acting as a video camera that replicates past experiences, memory is fragmentary and incomplete. Second, memory reconstruction is susceptible to distortion by a variety of influences independent of the information to be remembered. It is worth considering each of these points separately. The term "reconstruction" is used here, as in cognitive psychology and discourse processing, to refer to a fallible and indeterminate process of inference rather than the straightforward decoding mechanism envisioned by Ingarden (as described by 1995).

Elizabeth Loftus, among other researchers, exposed the flawed "memory as video camera" metaphor. In their classic investigation of eyewitness memory, Loftus and colleagues (1978) showed subjects a series of slides depicting a traffic accident, in one of which a red car appeared on a road in front of either a stop sign or a yield sign. Subjects were asked to pretend to be eyewitnesses to the scenes. They then answered questions about the slides, one of which linguistically presupposed the existence of either the stop sign or the yield sign (e.g., "Did another car pass the red Datsun while it was stopped at the stop sign?"). Subsequent recognition of the slides showed a substantial "misinformation effect": Recognition accuracy was $71 \%$ when the presupposition matched the original slide but only $41 \%$ when it mismatched. These results demonstrate that memory can be distorted by verbal information that is independent of the original perceptual experience.

Carmichael (1932) provided another demonstration of the influence of contextual information on memory retrieval. Subjects studied ambiguous line drawings (e.g., two circles connected by a straight line) along with verbal labels (e.g., "eye glasses" or "dumb bells"). Subsequently they were asked to draw the pictures from memory. 


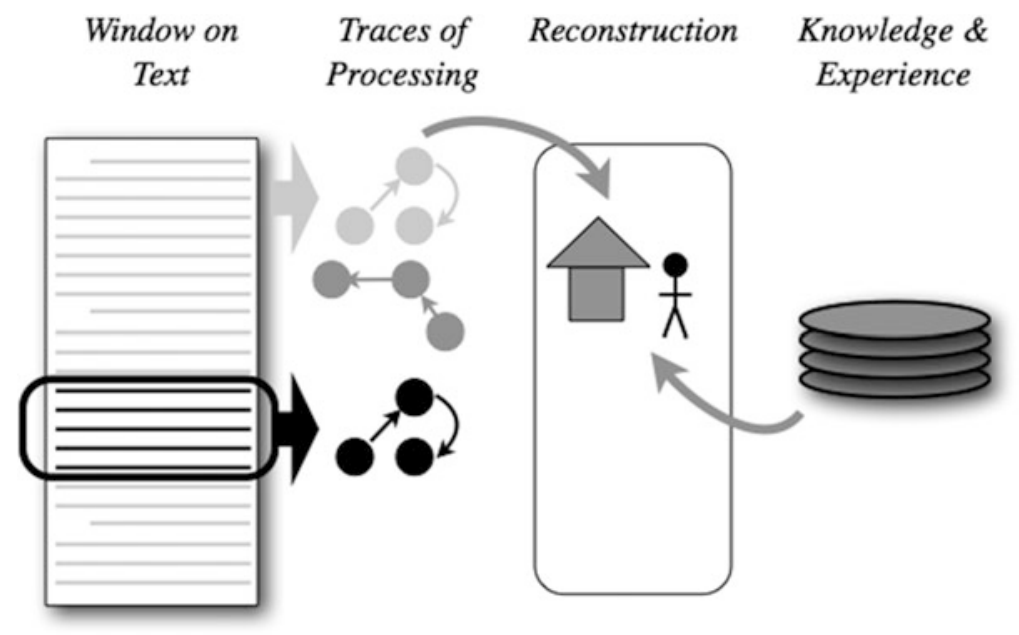

Fig. 1 Representations and processing in the comprehension of text. On the left is the immediately available text currently being processed; to the right are the traces of that processing; to the right of that is the story world situation as reconstructed from the memory traces and knowledge and experience

Results showed that their drawings from memory were affected by the nature of the label, independent of the perceptual information in the drawing. This result suggests that people do not retrieve some form of verbatim perceptual information from memory but rather that they must make inferences—-based on all sorts of available information-in order to reconstruct what they saw. The same must be true of text: Readers do not have a recording of what they have read, but rather must reconstruct that information from fragmentary memory traces.

These findings have serious implications for the processing and appreciation of literary narratives, some of which we illustrate in Fig. 1. The figure outlines why we can only reconstruct a schematic representation of the story we just read from the fragmentary traces of processing. On the left of the figure is the text. The highlighted lines indicate that limited portion of the text that is currently being processed. As described above, this is the only portion of the text that is immediately available for processing and inferences; material from earlier in the text must be reconstructed from memory. Just to the right of the text are processing traces that remain in memory. These are schematic representations of concepts and relationships rather than a verbatim copy of the words of the text. The traces near the top are depicted in light gray to suggest that traces become increasingly difficult to retrieve over time. Although we are mostly concerned with the traces of textual processing, as we discuss later, traces of other, extra-textual processing will also be found in memory. The actual representation of the situation and events described by the text are then reconstructed based on these traces; this is depicted in the box just to the right of memory traces. The depiction is intended to indicate simply a schematic situation model, or distilled representation, that has been reconstructed from the 
textual information we read. Further, as shown on the far right, comprehension and reconstruction rely substantially on world knowledge and personal experience. Thus, the schematic representation of the text will inevitably be intertwined with other knowledge. This means that the two can become confused (e.g., Bower et al. 1979). As with Carmichael's (1932) ambiguous pictures experiment, what is recalled is not a replica of the original experience, but rather a reconstruction that is based on other information besides the original processing. On balance, memory, either for past experience or for previously read text, is not only incomplete but also a function of a wide range of other information; the distilled outline that emerges in the reader's mind is at best a distorted reflection of the original narrative. The implication is that appreciation of the text and aesthetic response pertains to this reconstructed representation, not the text itself.

It must also be emphasized that memory is not only fragmentary and distorting, it is also ephemeral. Discourse processing studies have shown that memory for all aspects of text is short lived, making the mental representation of the read narrative more unreliable still. Three levels of memory representation have been identified: memory for surface structure, which dissipates almost immediately (e.g., by the end of a clause or sentence, Goldman et al. 1980); memory for the textbase, or propositional content, which has been shown to last a little longer (e.g., Singer and Kintsch 2001), and memory for the situation model, which lasts longer than the other two (cf. Zwaan et al. 1995). However, the situation model is far from complete or accurate. For example, Graesser and colleagues (1999a) demonstrated that memory for one critical aspect of the story, who said what in a story, is generally very poor, although it is better for the speech acts of first person narrators than for those of characters or third person narrators. In his classic experiment, Bartlett (1932) demonstrated that recall is very difficult and quite inaccurate when the material read was from a cultural background different from the reader's. These results were replicated more than four decades later (Kintsch and Greene 1978). Furthermore, it has been shown that the contextual knowledge at the time of reading has a great impact on memory and recall (Bransford and Johnson 1972). Graesser et al. (1999b) found that judgments concerning who knows what in the story are not a function of episodic memory (i.e., the ability to retrieve the speech act of agents in the story world) but were rather based on inference processes incorporating a range of different types of knowledge.

Together, these findings pose a serious challenge to approaches to literary response that include no role for the limitations of human memory. In literary studies, the topic of memory is only studied as a theme, such as the way in which memory for historical events is represented in specific literary works. The issue of how memory constrains the reading experience of real readers has received almost no attention in this field. Thus, scholarship in this tradition cannot provide an accurate account of reader processing. One of the few literary scholars who did foray into this terrain was Norman Holland (1975). In an informal study, he had five readers retell a story they had read, and found numerous changes in the retelling. This was taken as evidence that memory reconstructs rather than reproduces (cf. Bartlett 1932). Within the field of linguistics, Emmott (1997) acknowledged the 
limitation of real readers' memory in the reception of literature. She drew on cognitive psychology to better understand the mental activity of reading literature and reflected on "the minimum amount of textually presented information needed for the text to make sense" (p. 121). Apart from these limited exceptions, there has been relatively little rigorous, systematic study in linguistic and literary studies of the topic of memory for text.

As explained above, the general nature and role of memory have been studied extensively in discourse processing. Some attention has also been dedicated to the investigation of individual differences with respect to memory capacity. However, the contextual or situated determinants of textual memory have received less attention. Indeed, common theoretical approaches to reading in discourse processing often ignore the impact of context on reading, implying in effect an ideal reader and an idealized reading situation. In the following section we discuss the constraints that the situated nature of reading poses on the understanding and appreciation of literary texts.

\section{Text Processing in Context}

Reading and, by extension, readers are situated in the sense that reading does not occur in a vacuum; it transpires over time in both a mental and environmental context. Readers' mental states and factors peculiar to the environment necessarily affect processing. We describe two aspects of readers' mental states in particular that have an impact on the processing of the text: variations in attentional focus and variations in reading engagement.

Readers' mental states inevitably vary from moment to moment over the course of reading any text, a fact ignored by idealized concepts of the reader. For example, Nell (1988, p. 9) maintained that "because of the heavy demands reading makes on conscious attention, the reader is effectively shielded from other demands, whether internal or external." But in real-world reading contexts, external stimuli, such as even mundane changes in the environment-phones or doorbells ringing, temperature fluctuations, background noise-could alter a reader's priorities, causing a cessation of the reading or a decrease in attention. Other internal factors can also influence attentional resources devoted to the reading task. These include factors such as bodily needs, caffeine or lack of caffeine, the time of day, personal priorities, responsibilities, preoccupations, or even personal recollections prompted by the text (Dixon and Bortolussi 2015). Indeed, recent research on mind wandering has demonstrated that attention is never unwavering for any reader, under any circumstances. For example, Schooler, Reichle, and Halpern (2004) claimed that mind wandering can occur up to $23 \%$ of the time. Mind wandering varies with the interest value of the text but is still common for compelling and engaging texts (Dixon and Bortolussi 2013; see also Unsworth and McMillan 2013). As one might suspect, mind wandering has an important effect on memory for the text (Schooler 
et al. 2004; Dixon and Li 2013), reconstruction of the text during recall (Dixon and Bortolussi 2013), and inferences from the text (Smallwood et al. 2008).

Some of the effects of mind wandering can be understood with reference to Fig. 1. As discussed above, the read portions of the text are registered as traces in the reader's mind and must be distilled into a schematic outline of the narrative. However, mind wandering introduces processes, and memory traces of those processes, that are independent of the text. In the figure, these are depicted in the middle set of memory traces, unconnected to the text. Some of this processing may spring from personal preoccupations or desires, such as an up-coming trip or meeting with a difficult authority. Others may be prompted by the text itself: For example, a character in the story world might produce recollections and a mental image of someone known to the reader who in some way resembles that character. In other cases, passages may require the reader to stop and reflect on past experiences in an effort to understand some characters' thoughts, feelings, or behavior, and others still may prompt philosophical musings about human existence. Inevitably, this intermittent extra-textual processing affects the traces that are used during reconstruction, potentially interacting with memory for details of the text, and ultimately affecting the reader's ability to reconstruct the text.

Engagement is another mental state that may affect memory and the reconstruction of the text. Engagement-also known as narrative immersion, absorption, or transportation - has been the object of a variety of empirical investigations (e.g., Gerrig 1993; Green and Brock 2000; Green 2004; Green et al. 2004; Busselle and Bilandzic 2009; de Graaf et al. 2009; Tal-Or and Cohen 2010; Johnson 2012). The motivation of much of this work is to capture the idea that readers can be immersed in, intensely absorbed by, or engaged with the fictional world, experiencing it as if they had been transported into that world. English has its own expression to capture the phenomenon — "to be carried away by a book"—and, as Nell (1988, p. 50) has pointed out, many other languages have an equivalent expression. The idea itself is hardly new: Plato considered immersion a dangerous illusion (Herman et al. 2007). Since then, many literary scholars and critics have alluded to this notion to defend some essential point about the literary experience; transport is a property of some kinds of texts (Green and Brock 2000, p. 719) or a requirement for meaningful, productive reading experiences.

Some of these studies stress the mechanisms that enable the experience of immersion, particularly simulation and emotional involvement (Currie and Ravenscroft 2002; Herman et al. 2007; Bal and Veltkamp 2013). Others stress the effects of transport, including increased appreciation and deeper processing (Craik and Lockhart 1972; Busselle and Bilandzic 2009), although some have reported that cognitive depth and transport are conflicting processes (Green and Brock 2000). More recently, Janit (2011) suggested that transportation might lead to better memory for text. However, since the materials used in Janit's study were stories in textbooks, more research with literary narratives is needed before we can reliably conclude that transport into fictional worlds has a beneficial effect on memory for text more generally. Some of the alleged effects include attitudinal and behavioral 
changes (Appel and Richter 2007; Johnson 2012). In all of these accounts, it is taken for granted that transportation entails the full attention of the reader; readers are described as being so focused on the reading that they are even unaware of their immediate surroundings. The metaphor suggests deeper processing; presumably readers lose track of their surroundings because their minds are actively engaged in processing the text.

As we argued elsewhere, the transport metaphor has become so entrenched and naively accepted that it is no longer questioned (Bortolussi and Dixon 2015). Yet many questions have not been adequately addressed, if at all. For example, does transport necessarily entail sustained attention? Does emotional engagement always enhance attention to and memory for textual details, or might a gripping scene cause the reader to divert attentional resources from some textual features, such as linguistic or stylistic devices and reallocate them to emotional musings? How, specifically, are attentional resources distributed, and, concretely, what aspects of the text that are read in an engaged state are remembered? In fact, empirical studies of literature devoted to transportation bear much in common with traditional literary studies in terms of assumptions about the nature of the text: Transportation is a property of certain texts or the capacities of the reader; readers have the ability to sustain focus and attention; and there is an optimal text-reader relationship in which readers respond as intended. But transportation is not necessarily a property of certain kinds of texts, that is, a unitary phenomenon that may or may not happen for any given story. Rather, attention and engagement are more likely to vary across texts in accordance with textual shifts and changes; for example, some portions of any given text might be more evocative than others in the same text. While it is logical to assume that writers produce fiction for the purpose of inducing transportation and artfully employ techniques to achieve that purpose, whether and to what extent readers notice, track, associate, and process them accordingly is an empirical question.

More generally, the relationship between reading focus and engagement has not been carefully articulated. Although it seems intuitive that being engaged involves attending to the material, these variables need not be the same. For example, one may be engaged with the story in the sense of thinking deeply about the situation and characters and attempting to analyze and understand the relationships in the story world. However, such processing might mean actually paying less attention to the details that are presented in the text. Indeed, such details may be suppressed if they are inconsistent with the broader inferences drawn by the reader. For example, Green and Brock (2000, p. 711) argued that engaged readers "appeared more accepting of the story" and were "less likely to doubt, to question, or to engage in disbelieving processing." Under other circumstances, being engaged might entail considering personal experiences related to the story; a form of mind wandering would ensue if such considerations become deeply involving. Conversely, one could carefully focus on the text without generating much in the way of an understanding of the story and its more profound implications. In this case, the reader would generate only a superficial representation of the story-world events. Thus, it is plausible that under at least some circumstances, textual engagement is not tantamount to reading focus. 
One possibility is that neither does engagement imply focusing on the text, nor does reading focus imply engagement. Instead, both processes may be determined by other factors. (de Graaf et al. 2009 considers some related complexities). In particular, it seems reasonable to suppose that one such variable is the interest value of the text (Hidi and Baird 1986). For example, if readers find the material interesting, they are likely to focus on the material more carefully (Giambra and Grodsky 1989). Similarly, the relationship of the text to the reader (which presumably determines reader interest) has been shown to be related to engagement (Green 2004). Thus, although it is intuitive that readers will more likely appreciate a text in which they are interested, it is critical to consider the variables that are likely to mediate that relationship, among them, engagement and focus.

\section{Evidence on Mind Wandering and Engagement}

In the following, we describe two empirical studies that demonstrate the importance of mind wandering and engagement in memory for the text. As we discussed at the outset, memory is the basis for any kind of literary interpretation, and hence any aspect of processing that affects memory can be a factor in interpretation. We used two texts, one that was likely to be of interest to our readers and one that was likely to be relatively uninteresting. Our general goal is to explore how variations in processing over the course of the text affect memory. Both experiments employ what might be termed a mental-state probe procedure in which subjects are occasionally interrupted while reading and asked to report on the nature of their mental state (e.g., Teasdale et al. 1995).

\subsection{Method}

We asked separate groups of subjects to read an interesting story (the initial 7,342 words of Interview with the Vampire by Ann Rice) or a less interesting story (the initial 7,753 words of The Story of Pendennis by William Makepeace Thackery). (Our description of Interview as interesting and Pendennis as less interesting is based on our intuitive judgment but was borne out by the reactions of subjects to these materials.) In Experiment 1, 19 subjects read Interview and 18 read Pendennis; data from 10 other subjects were not used because they appeared to be skimming large portions of the text. In Experiment 2, 21 subjects read Interview and 14 read Pendennis; data from 9 other subjects were not used because they were skimming. The texts were read on a computer screen one sentence at a time. After reading each sentence, the subject pressed the spacebar to continue on with the next sentence. At ten unpredictable locations in the text, instead of the next sentence, subjects were asked about their mental state. The mental state probe in 
Experiment 1 took the form of the question, "Were you fully comprehending the story or were you thinking of something else?" Underneath the question was a line with points labeled with: "Definitely thinking of something else," "Thinking of something else to some extent," "Not sure," "Comprehending to some extent," and "Definitely comprehending." Subjects used a computer mouse to click somewhere along this line. The response that was measured was a number, ranging from -225 to +225 , indicating the position (in pixels) along the response scale where subjects clicked. Experiment 2 was precisely the same except that the question used was, "Do you feel like you're experiencing the story as if you were there or are you just reading superficially?" Points along the response scale were labeled with: "Definitely reading superficially," "Reading superficially to some extent," "Not sure," "Experiencing the story to some extent," and "Definitely experiencing the story."

After reading the text, subjects were given 20 multiple-choice questions. There were two questions concerning the material just prior to each of the mental-state probes. Thus, accuracy on the questions could be compared to the probe response that was made previously. For example, in Experiment 1, when a subject responded to a probe by indicating that he or she was on task, one would expect the subject to have less difficulty with the questions pertaining to the just-completed material. Similarly, in Experiment 2, when a subject responded to a probe by indicating that he or she was engaged with the story, one might expect the subject to be more accurate for that material.

\subsection{Results}

Briefly, the results of the first experiment show what we intuitively would expect, that is, that the more interesting story produced higher on-task ratings. Further, better memory occurs when the on-task ratings are the highest. Critically, being on task appears to be the sole determinant of memory: The more interesting story does not, by itself, lead to better memory.

The pattern of results is shown in Fig. 2. There are four aspects of this figure that deserve explanation. First, for a variety of statistical reasons, the accuracy of the subjects' response to the memory questions was measured in log odds correct. For comparison, on a log odds, or logit, scale, $50 \%$ correct would be $0,75 \%$ correct would be 1.1, and $90 \%$ would be 2.2. In Fig. 2, although subjects' responses were substantially better than chance, they were far from perfect: Accuracy scores in the figure ranged from about .5 to 1.0 logits. Second, the on-task response is shown along the horizontal axis, with higher values indicating greater focus on the text. Thus, values at the right of the graph (higher on-task rating) should go with higher values on the vertical axis (more accurate memory). This general trend was found, although the increase in accuracy was not substantial unless the on-task rating was fairly high. Third, for each story, we divided all of the responses into a high 


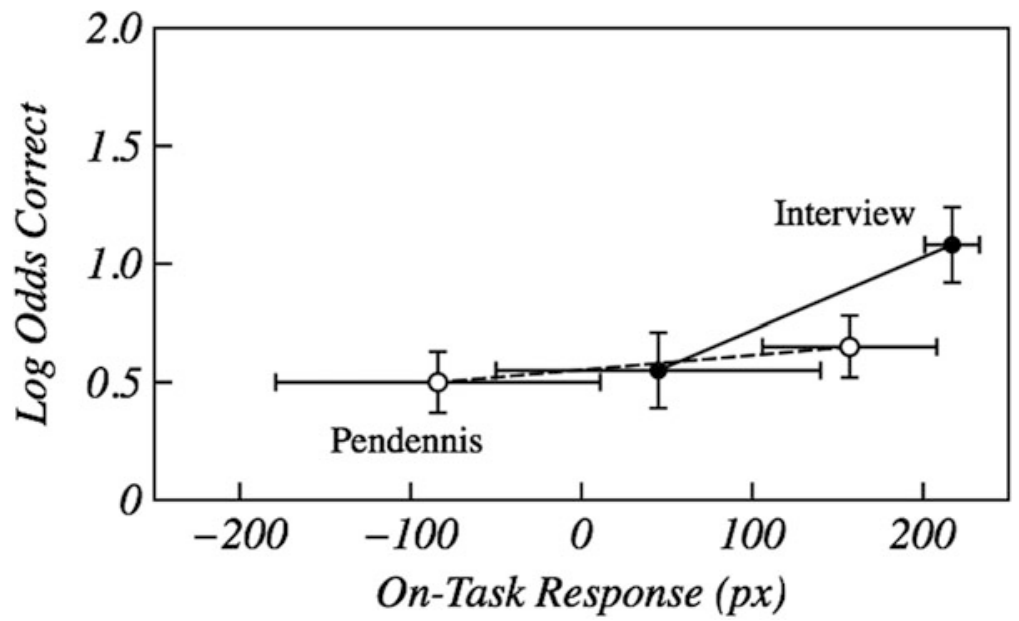

Fig. 2 Memory accuracy (in terms of $\log$ odds correct) in Experiment 1 as a function of story and on-task probe response

group and a low group based on a median split. In order to indicate how spread out each group was, the standard deviation of the scores in each group is plotted as a horizontal error bar in the figure. As described above, subjects were more on task with the interesting story (Interview, shown with the solid circle and line) than with the less interesting story (Pendennis, shown with open circles and dotted line). In effect, interesting stories keep subjects on task. Fourth, for each high and low group, the overall accuracy associated with those responses is shown by the vertical position. The vertical error bar indicates the standard error of the accuracy as derived from a statistical model fit. Although accuracy is relatively unrelated to on-task response over most of the range, very high levels of on-task response (the rightmost point for Interview) is associated with some improvement in memory.

We turn now to the results of the second experiment in which engagement was probed. In this case, the results were different in several important ways. As expected, subjects were more likely to be engaged with the more interesting Interview than with Pendennis. Moreover, memory was better for Interview; this can be seen as replicating the effect of interest value found in Experiment 1. However, engagement by itself had little impact on memory. For both stories, more engagement had little positive (and perhaps even a negative) effect on memory. In this sense, being engaged is quite different from being focused on the text.

Figure 3 shows this pattern of results in a manner analogous to the previous figure. Not surprisingly, Interview lead to greater engagement than the more tedious (for our subjects) Pendennis; thus, the Interview responses are generally to the right of the Pendennis responses. However, unlike the on-task rating, there was no relationship between engagement and later memory for either story by itself. This is depicted in the figure by the slope of the Pendennis line and the slope Interview 


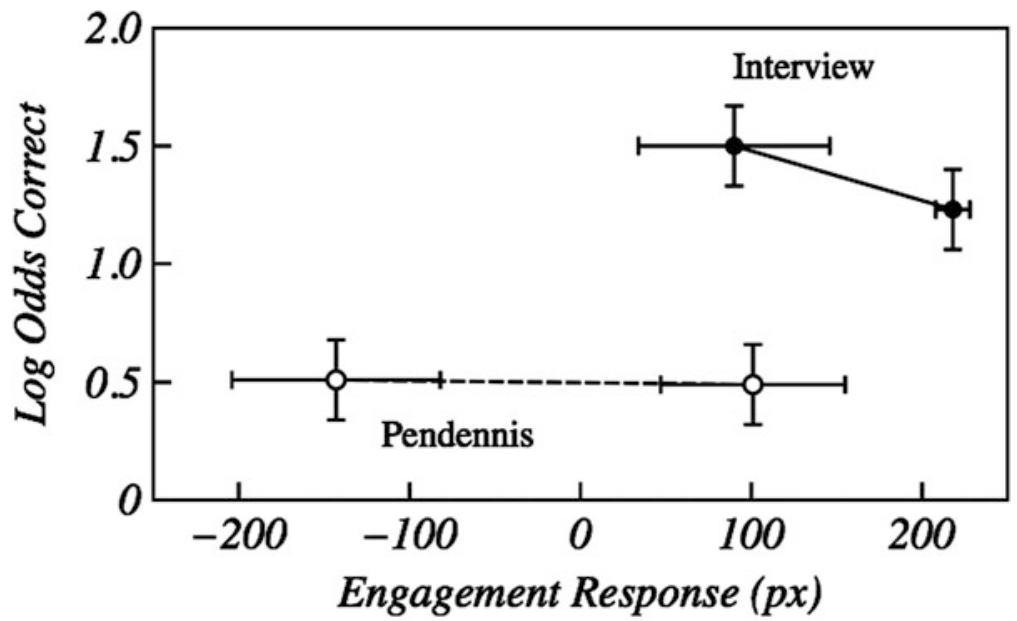

Fig. 3 Memory accuracy (in terms of log odds correct) in Experiment 2 as a function of story and engagement probe response

line: Neither slopes up as would be expected if engagement affected memory. In other words, greater engagement with a given story did not produce better memory. Indeed, there was a small trend for greater engagement with Interview to be associated with weaker memory. There was, of course, an overall difference between stories: Interview was remembered better than Pendennis. However, the results make clear that this difference is not due to greater engagement. This is a surprising revelation.

\subsection{Discussion}

The results from the two experiments illuminate how memory is affected by mental processing over the course of the text. The first experiment demonstrated that high levels of attention to the task can lead to improved memory for the text. This, of course, is perfectly intuitive: If you want to remember what you are reading, you should concentrate on the material. However, there are two constraints on this intuitive interpretation. First, the effect on memory was fairly modest and only occurred at the very extreme of the on-task scale. Overall, being on task had a relatively small effect on our measure of memory. Second, there was no independent effect of interest value on memory. Although memory was generally better for Interview, the results suggest that the story led subjects to focus on the material more, and this increase in attention led to better memory. For example, in Fig. 2, the high on-task group for Pendennis had the same on-task rating as the low group for Interview, and the result was comparable levels of memory. In contrast, Experiment 
2 demonstrated that this was not the case when engagement was measured. Although the more interesting story was rated as more engaging and that story was more memorable, within each story, engagement had no effect on memory.

Making sense of this pattern of results requires a careful analysis of the causal connections in the processing of the text. Our interpretation is illustrated in Fig. 4. We selected two texts that we assumed varied in interest value. In turn, the interest value had clear effects on both the extent to which subjects focused on the story and the degree of engagement. Memory, on the other hand, seemed to be only related to focus, not whether or not they were deeply engaged with the story world. Thus, while engagement might make for a more memorable reading experience, it doesn't necessarily lead to a better recollection of story details. Our memory test was designed to assess the quality of the memory traces (being based on textual details) rather than the reconstructed situation in the story world.

This is not to say that engagement has no effect on reading. On the contrary, we suspect that being engaged with a story leads to a more elaborate and detailed representation of the story world, one that makes a greater use of world knowledge and personal experience. In other words, the reconstructed representation in Fig. 1 would be elaborate and extensive when readers are engaged with the story world. This is illustrated in Fig. 4 by causal connections from both engagement and memory to reconstruction. In other research, we have found evidence for more elaborate story-world representations when engaged: The more engaging a story is, the better subjects are at recalling the story rather than simply recognizing details (Dixon and Bortolussi 2013). Finally, Fig. 4 illustrates our overarching point that any appreciation of the text must depend on the reconstructed story, not the text itself. The appreciation of a story must necessarily be mediated by a complex of processes and memory representations.

Fig. 4 Hypothesized causal relationships. Interest leads to an increase in on-task processing and engagement; being on task (but not engagement) leads to better memory; reconstruction depends on both memory traces and engagement; and reconstruction provides the basis for appreciation

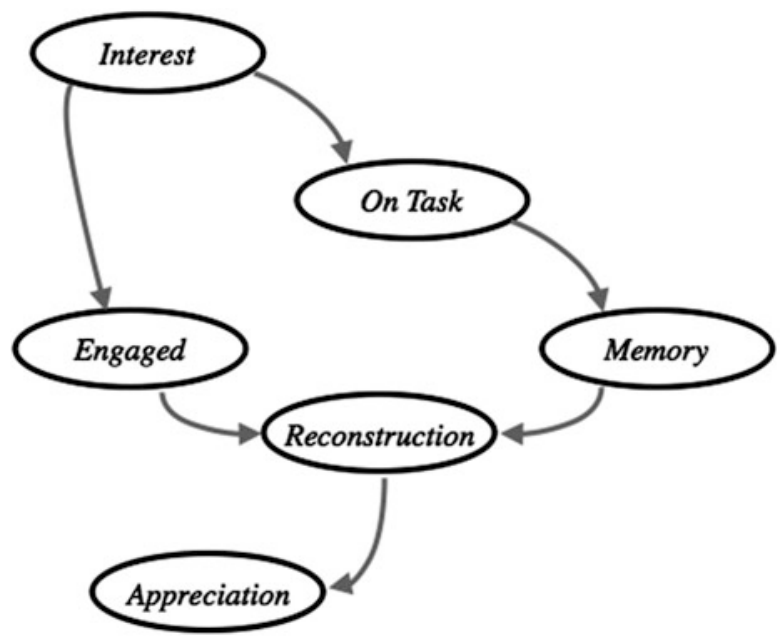




\section{Conclusions}

We began with a brief review of the phenomenological legacy in theoretical accounts of literary processing. Phenomenology, explained simply, "is the way in which human beings come to understand the world through direct experience- the perception of a phenomenon, whether an object, event, or condition" (Littlejohn and Foss 2011, p. 47). For early proponents of a phenomenological approach to literary studies, such as Ingarden (1931) and Iser (1974), the object of the experience was the text. One can infer from their works that competent, alert readers can potentially be aware of everything in the text as well as their mental actions on the text. In other words, appreciation of literature was mediated by what the reader had available in consciousness and what was in consciousness was dictated precisely by what was in the text. In contrast, we are concerned with the complexities of how the mind is known to work. We know, for example, that awareness, perception, attention, and memory are limited, and that the use of these capacities varies dynamically over time. Thus, a variety of mental mechanisms intervene between the text and the reader's appreciation, and many of these mechanisms operate without awareness. We cannot, in fact, have an account of appreciation based simply on conscious introspection. We have shown how the understanding and interpretation of literary texts requires memory and have discussed the welldocumented limitations of memory: Memory traces are fragmentary and ephemeral and the reader's representation of the story world must be reconstructed based on a variety of extra-textual sources of information (cf. Bortolussi and Dixon 2013). To these limitations, we add the varying mental states of the reader. He or she may or may not focus on the text at any point in time, and he or she may or may not be fully engaged with the story. These mental states have implications for what processing traces are available in memory and how this information is used in reconstruction. Further, the mind supplements textual information with extra-textual input, and confuses what is in the text with what is not. Readers notice what is of interest or relevant to them, filter out what is not, and can draw unpredictable connections. In other words, we process literature in terms of how we interact with it. Each reader's interaction is selective.

A serious endorsement of these limitations of the real reader's mind has extensive implications for the understanding of literary processing. Perhaps one of the most interesting is that aesthetic reaction is not to the text, but rather to readers' mental representation in memory, and that this mental representations bears a pale resemblance to the original. What is produced in the reader's mind can never, for any reader under any circumstances, be the equivalent of the text. Rather than bemoan this reality, as literary theorists might, we should instead recognize that it is that very outcome of the reading process - the mental representation-that makes literature memorable: Readers interact with the text, bringing themselves to it, so that the product of their processing is a unique combination of the objective and subjective, of the text and themselves. 
Although our understanding of the reader's mental states is only beginning, there is no question that such an understanding is fundamental to a description of literary processing. In order to understand the nature of a reader's literary appreciation, we cannot depend on the phenomenological supposition that appreciation is available to the conscious mind. Rather, the phenomena of appreciation among real readers must be understood only with carefully designed empirical evidence.

Open Access This chapter is distributed under the terms of the Creative Commons Attribution Noncommercial License, which permits any noncommercial use, distribution, and reproduction in any medium, provided the original author(s) and source are credited.

\section{References}

Appel, Markus, and Tobias Richter. 2007. Persuasive effects of fictional narratives increase over time. Media Psychology 10(1): 113-134.

Bal, Mieke. 1977. Narration et focalisation. In Narratologie. Essais Sur La Signification Narrative Dans Quatre Romans Modernes. Paris: Klincksieck.

Bal, P. Matthijs, and Martijn Veltkamp. 2013. How does fiction reading influence empathy? An experimental investigation on the role of emotional transportation. PLOS ONE 8(1): e55341.

Bartlett, Frederic C. 1932. Remembering: A study in experimental and social psychology. Cambridge: Cambridge University Press.

Bortolussi, Marisa, and Peter Dixon. 2013. Minding the text: Memory for literary narrative. In Stories and minds: Cognitive approaches to literary narrative, ed. Lars Bernaerts, Dirk de Geest, Luc Herman, and Bart Vervaeck. Lincoln: University of Nebraska Press.

Bortolussi, Marisa, and Peter Dixon. 2015. Transport: Challenges to the metaphor. In The Oxford handbook of cognitive literary studies, ed. Lisa Zunshine. Oxford: Oxford University Press.

Bower, Gordon H., John B. Black, and Terrence J. Turner. 1979. Scripts in memory for text. Cognitive Psychology 11(2): 177-220.

Bransford, John D., and Marcia K. Johnson. 1972. Contextual prerequisites for understanding: Some investigations of comprehension and recall. Journal of Verbal Learning and Verbal Behavior 11(6): 717-726.

Bronzwaer, William J.M. 1981. Mieke Bal's concept of focalization: A critical note. Poetics Today 2(2): 193-201.

Bundgaard, Peer F. 2013. Roman Ingarden's theory of reader experience: A critical assessment. Semiotica 194: 171-188.

Busselle, Rick, and Helena Bilandzic. 2009. Measuring narrative engagement. Media Psychology 12(4): 321-347.

Carmichael, Leonard, H.P. Hogan, and A.A. Walter. 1932. An experimental study of the effect of language on the reproduction of visually perceived form. Journal of Experimental Psychology 15(1): 73.

Craik, Fergus I.M., and Robert S. Lockhart. 1972. Levels of processing: A framework for memory research. Journal of Verbal Learning and Verbal Behavior 11(6): 671-684.

Culler, Jonathan D. 1975. Structuralist poetics: Structuralism, linguistics and the study of literature. London: Routledge \& Keegan Paul.

Currie, Gregory, and Ian Ravenscroft. 2002. Recreative minds: Imagination in philosophy and psychology. Oxford: Oxford University Press.

de Graaf, Anneke, Hans Hoeken, José Sanders, and Hans Beentjes. 2009. The role of dimensions of narrative engagement in narrative persuasion. Communications 34(4): 385-405. 
Dixon, Peter, and Henry Li. 2013. Mind wandering in text comprehension under dual-task conditions. Front Psychology 4(682): 1-14.

Dixon, Peter, and Marisa Bortolussi. 2013. Construction, integration, and mind wandering in reading. Canadian Journal of Experimental Psychology 67(1): 1-10.

Dixon, Peter, and Marisa Bortolussi. 2015. Fluctuation in literary reading: The neglected dimension of time. In The Oxford handbook of cognitive literary studies, ed. Lisa Zunshine. Oxford: Oxford University Press.

Emmott, Catherine. 1997. Narrative comprehension: A discourse perspective. Oxford: Oxford University Press.

Escarpit, Robert. 1966. The book revolution. London: Harrap.

Fletcher, Charles R. 1986. Strategies for the allocation of short-term memory during comprehension. Journal of Memory and Language 25(1): 43-58.

Fludernik, Monika. 2001. New wine in old bottles? Voice, focalization and new writing. New Literary History 32(3): 619-638.

Gerrig, Richard J. 1993. Experiencing narrative worlds. New Haven: Yale University Press.

Giambra, Leonard M., and Alicia Grodsky. 1989. Task-unrelated images and thoughts while reading. In Imagery: Current perspectives, ed. Joseph E. Shorr, Penee Robin, Jack A. Connella, and Milton Wolpin. New York: Plenum Press.

Goldman, Susan R., Thomas W. Hogaboam, Laura C. Bell, and Charles A. Perfetti. 1980. Shortterm retention of discourse during reading. Journal of Educational Psychology 72(5): 647-655.

Graesser, Arthur C., Cheryl Bowers, Brent Olde, and Victoria Pomeroy. 1999a. Who said what? Source memory for narrator and character agents in literary short stories. Journal of Educational Psychology 91(2): 284.

Graesser, Arthur C., Cheryl Bowers, Brent Olde, Katherine White, and Natalie K. Person. 1999b. Who knows what? Propagation of knowledge among agents in a literary story world. Poetics 26(3): 143-175.

Green, Melanie C. 2004. Transportation into narrative worlds: The role of prior knowledge and perceived realism. Discourse Process 38(2): 247-266.

Green, Melanie C., and Timothy C. Brock. 2000. The role of transportation in the persuasiveness of public narratives. Journal of Personality and Social Psychology 79(5): 701-721.

Green, Melanie C., Timothy C. Brock, and Geoff F. Kaufman. 2004. Understanding media enjoyment: The role of transportation into narrative worlds. Communication Theory 14(4): 311-327.

Herman, Luc, and Bart Vervaeck. 2004. Focalization between classical and postclassical narratology. In The dynamics of narrative form: Studies in Anglo-American narratology, ed. John Pier. Berlin: Walter de Gruyter.

Herman, David, Manfred Jahn, and Marie-Laure Ryan. 2007. Routledge encyclopedia of narrative theory. London: Routledge.

Hidi, Suzanne, and William Baird. 1986. Interestingness: A neglected variable in discourse processing. Cognitive Science 10(2): 179-194.

Holland, Norman Norwood. 1975. Five readers reading. New Haven: Yale University Press.

Holub, Robert. 1995. Phenomenology. In From formalism to poststructuralism, The Cambridge history of literary criticism, vol. 8, ed. Raman Selden. Cambridge/New York: Cambridge University Press.

Ingarden, Roman. 1931/1973. The literary work of art: An investigation on the borderlines of ontology, logic, and theory of literature. Evanston: Northwestern University Press.

Iser, Wolfgang. 1974. The implied reader: Patterns of communication in prose fiction from Bunyan to Beckett. Baltimore: Johns Hopkins University Press.

Iser, Wolfgang. 1978. The act of reading. Baltimore: Johns Hopkins University Press.

Janit, Adrian S., Georgina S. Hammock, and Deborah S. Richardson. 2011. The power of fiction: Reading stories in abnormal psychology. International Journal for the Scholarship of Teaching and Learning 5(1): 1-14. 
Johnson, Dan R. 2012. Transportation into a story increases empathy, prosocial behavior, and perceptual bias toward fearful expressions. Personality and Individual Differences 52(2): $150-155$.

Kintsch, Walter, and Edith Greene. 1978. The role of culture-specific schemata in the comprehension and recall of stories. Discourse Process 1(1): 1-13.

Klauk, Tobias. 2012. The pragmatics of internal focalization. Style 46(2): 229-246.

Leech, Geoffrey Neil, and Mick Short. 2007. Style in fiction: A linguistic introduction to English fictional prose. Harlow: Pearson Education.

Littlejohn, Stephen W., and Karen A. Foss. 2011. Theories of human communication. Long Grove: Waveland Press.

Loftus, Elizabeth F., David G. Miller, and Helen J. Burns. 1978. Semantic integration of verbal information into a visual memory. Journal of Experimental Psychology: Human Learning and Memory 4(1): 19.

Margolin, Uri. 2009. Focalization: Where do we go from here? In Point of view, perspective, and focalization: Modelling mediation in narrative, ed. Peter Hühn, Wolf Schmid, and Jörg Schönert. Berlin: Walter de Gruyter.

Miall, David S., and Don Kuiken. 1994. Foregrounding, defamiliarization, and affect: Response to literary stories. Poetics 22(5): 389-407.

Nell, Victor. 1988. Lost in a book: The psychology of reading for pleasure. New Haven: Yale University Press.

Nieragden, Göran. 2002. Focalization and narration: Theoretical and terminological refinements. Poetics Today 23(4): 685-697.

Sanford, Anthony J., and Catherine Emmott. 2012. Mind, brain and narrative. Cambridge: Cambridge University Press.

Schooler, Jonathan W., Erik D. Reichle, and David V. Halpern. 2004. Zoning out while reading: Evidence for dissociations between experience and metaconsciousness. In Thinking and seeing: Visual metacognition in adults and children, ed. Daniel T. Levin. Cambridge: MIT Press.

Singer, Murray, and Walter Kintsch. 2001. Text retrieval: A theoretical exploration. Discourse Process 31(1): 27-59.

Smallwood, Jonathan, Merrill McSpadden, and Jonathan W. Schooler. 2008. When attention matters: The curious incident of the wandering mind. Memory \& Cognition 36(6): 1144-1450.

Tal-Or, Nurit, and Jonathan Cohen. 2010. Understanding audience involvement: Conceptualizing and manipulating identification and transportation. Poetics 38(4): 402-418.

Teasdale, John D., Barbara H. Dritschel, Melanie J. Taylor, Linda Proctor, Charlotte A. Lloyd, Ian Nimmo-Smith, and Alan D. Baddeley. 1995. Stimulus-independent thought depends on central executive resources. Memory \& Cognition 23(5): 551-559.

Unsworth, Nash, and Brittany D. McMillan. 2013. Mind wandering and reading comprehension: Examining the roles of working memory capacity, interest, motivation, and topic experience. Journal of Experimental Psychology: Human Learning and Memory 39(3): 832-842.

van Peer, Willie. 1986. Stylistics and psychology: Investigations of foregrounding. In Stylistics and psychology: Investigations of foregrounding. London: Croom Helm

Zunshine, Lisa. 2006. Why we read fiction: Theory of mind and the novel. Columbus: Ohio State University Press.

Zwaan, Rolf A., Mark C. Langston, and Arthur C. Graesser. 1995. The construction of situation models in narrative comprehension. Psychological Science 6(5): 292-297. 